\title{
Retrieval and sleep both counteract the forgetting of spatial information
}

\author{
James W. Antony ${ }^{1,2}$ and Ken A. Paller ${ }^{1,3}$ \\ ${ }^{1}$ Interdepartmental Neuroscience Program, Northwestern University, Evanston, Illinois 60208, USA; ${ }^{2}$ Princeton Neuroscience \\ Institute, Princeton University, Princeton, New Jersey 08544, USA; ${ }^{3}$ Department of Psychology, Northwestern University, Evanston, \\ Illinois 60208, USA
}

\begin{abstract}
Repeatedly studying information is a good way to strengthen memory storage. Nevertheless, testing recall often produces superior long-term retention. Demonstrations of this testing effect, typically with verbal stimuli, have shown that repeated retrieval through testing reduces forgetting. Sleep also benefits memory storage, perhaps through repeated retrieval as well. That is, memories may generally be subject to forgetting that can be counteracted when memories become reactivated, and there are several types of reactivation: (i) via intentional restudying, (ii) via testing, (iii) without provocation during wake, or (iv) during sleep. We thus measured forgetting for spatial material subjected to repeated study or repeated testing followed by retention intervals with sleep versus wake. Four groups of subjects learned a set of visual object-location associations and either restudied the associations or recalled locations given the objects as cues. We found the advantage for restudied over retested information was greater in the PM than AM group. Additional groups tested at 5-min and 1-wk retention intervals confirmed previous findings of greater relative benefits for restudying in the short-term and for retesting in the long-term. Results overall support the conclusion that repeated reactivation through testing or sleeping stabilizes information against forgetting.
\end{abstract}

A fundamental aspect of memory is that it degrades over time. One way to prevent degradation is to repeatedly reengage with the same material after initial encoding. Numerous studies and memory theories have focused on memory differences following two types of reengagement-restudying and testing without feedback. For example, a student might attempt to master some material learned during a lecture by reading notes taken during the lecture or by attempting to recall some of the material without the notes. Students often prefer the former strategy, but it can produce inflated impressions of one's mastery of the material (Karpicke and Roediger 2008). Moreover, on tests taking place within an hour of learning, restudying typically produces superior retrieval compared to testing without feedback (Roediger and Karpicke 2006a; Kornell et al. 2011; Bai et al. 2015). After delays longer than a few hours, however, testing benefits memory more than restudying, a phenomenon known as the "testing effect" (Abbott 1909; Gates 1917; Spitzer 1939; Carrier and Pashler 1992; Roediger and Karpicke 2006b; Carpenter et al. 2008).

With the passage of time after learning, memories can become less accessible, while exposure to interfering information is known to directly interfere with memory accessibility (i.e., retroactive interference). Interestingly, testing protects memories from retroactive interference (Potts and Shanks 2012), and tasks that add retroactive interference between encoding and practice tests increase the relative stability of tested, as opposed to restudied, information (Halamish and Bjork 2011). These studies show that varying amounts of interference can modulate the relative strength of tested versus restudied information while controlling for the passage of time.

Another way to vary interference while controlling for the passage of time involves measuring memory performance across a sleep or wake interval. Intervals of sleep have been repeatedly shown to preserve declarative memories relative to intervals of

Corresponding author: jantony@princeton.edu

Article is online at http://www.learnmem.org/cgi/doi/10.1101/lm.046268.117. wakefulness (Jenkins and Dallenbach 1924; Yaroush et al. 1971; Benson and Feinberg 1977; Plihal and Born 1997). Predominant models propose that memories are reactivated during sleep, leading to their stabilization (Diekelmann and Born 2010; Oudiette and Paller 2013). Interestingly, sleep may preferentially aid weaker memories that still need to be recalled (Norman et al. 2005; van de Ven et al. 2016). For instance, greater encoding difficulty increases benefits of sleep relative to wakefulness (Schmidt et al. 2006; Payne et al. 2012a), and reactivating memories with cues during sleep results in greater benefits for memories of intermediate than high accuracy prior to sleep (Creery et al. 2014).

Though restudy often benefits memory relative to retrieval in the short-term, the long-term benefits of retrieval suggest restudied information may be less stabilized. Therefore, sleep may benefit restudied more than retrieved information. Bäuml et al. (2014) convincingly showed across a series of experiments that restudied information benefits more than tested information over sleep than wake. They interpreted their findings to indicate that sleep decreases the testing effect. However, they also noted an alternative interpretation-rather than crediting sleep, it could be that prolonged wake enhances interference, resulting in an increased relative preservation of tested items. Because they did not include a 24-h condition, they were unable to directly test this possibility.

Here we investigated the interaction of learning strategy and sleep on memory. Although most studies of testing effects have used verbal information, we used spatial information, for which testing effects have also been found (Carpenter and Kelly 2012). In our study, learning occurred in the morning or evening, with a final test after either a 12- or 24-h retention interval (Fig. 1A), allowing us to test the competing accounts posed above.

(C) 2018 Antony and Paller This article is distributed exclusively by Cold Spring Harbor Laboratory Press for the first 12 months after the full-issue publication date (see http://learnmem.cshlp.org/site/misc/terms.xhtml). After 12 months, it is available under a Creative Commons License (Attribution-NonCommercial 4.0 International), as described at http://creativecommons.org/licenses/by-nc/ $4.0 /$ 
A

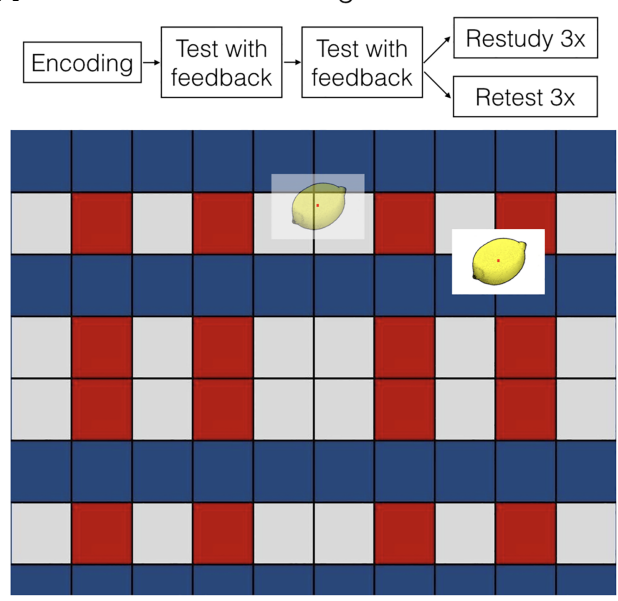

B

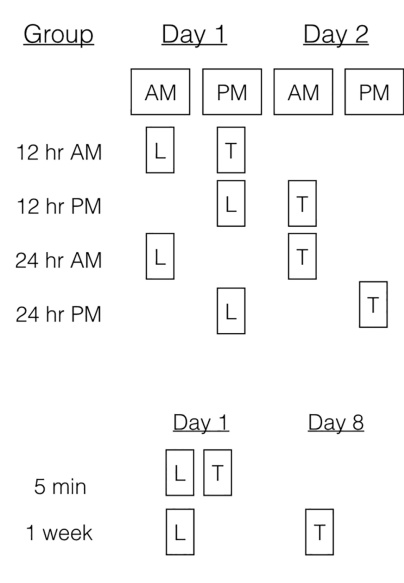

Figure 1. Paradigm and experimental overview. $(A)$ During learning, subjects encoded the location of objects, took practice tests with feedback, and then either restudied or retested on each object again without feedback. An example test trial is shown below, with an object shown where it might have been placed on the grid, as well as in its original location (shown as feedback). After this learning session $(\mathrm{L})$, they returned to the laboratory to take a final test $(T)$, as shown in $(B)$ for each of the six groups.

Immediately after initial learning, object-location associations were restudied $(S)$ or retested $(\mathrm{T})$ thrice more before the final test. We thus contrasted retention as a function of both the testing effect and whether the retention interval included sleep. In line with the findings of Bäuml et al. (2014), we hypothesized a relative preservation of restudied versus retested items during sleep, giving rise to a preferential benefit for restudied versus retested information in the 12-h PM group (sleep during the retention interval) versus the 12-h AM group (no sleep during the retention interval). Results could thus be used to test the alternative interpretation that wake enhances the benefits of testing, rather than that sleep reduces them.

Additionally, we hypothesized memory would be better for restudied information after 5-min intervals and retested information at intervals longer than a few hours, as is typical for the testing effect (Wheeler et al. 2003; Roediger and Karpicke 2006a; Kornell et al. 2011; Bai et al. 2015). To further verify the time course of forgetting, we included two additional groups of subjects at retention intervals of $5 \mathrm{~min}$ and $1 \mathrm{wk}$.

\section{Results}

\section{No circadian effects on acquisition}

To check for a circadian influence on learning, we analyzed the number of trials required for subjects to reach criterion. We found no difference between AM and PM sessions [179.2 \pm 5.2 and 192.9 \pm 10.0 trials, respectively; $\left.t_{(62)}=1.2, P=0.22, d=0.3\right]$.

\section{Retrieval slightly worsened across repeated practice tests}

As practice occurred without feedback, mean spatial error increased across trials (first: $98.8 \pm 3.5$ pixels; second: $104.5 \pm 3.7$ pixels; third: $107.8 \pm 4.2 ; F(1,63)=13.6, P<0.001)$. This indicates performance slightly but reliably worsened across repeated tests.

\section{Retention interval and learning strategy affected memory, but time of encoding did not}

We next investigated how our three main independent variables affected memory using a three-way, retention interval (12-h
We next followed up our main prediction that sleep compared to wake would preferentially benefit restudied versus retested information. We tested this with a two-way, time of encoding (AM versus $\mathrm{PM}$ ) $\times$ memory strategy ( $\mathrm{S}$ versus T) ANOVA within 12-h groups. We found a significant main effect of memory strategy $\left[F_{(1,29)}=\right.$ $16.4, P<0.001]$, no main effect of time of encoding $\left[F_{(1,29)}=0.61\right.$, $P=0.43]$, and, critically, a significant interaction between the factors $\left[F_{(1,29)}=4.6, P=0.040\right]$. Follow-up $t$-tests featuring direct comparisons between restudied items in the AM versus PM group were not significant $\left[t_{(29)}=1.6, P=0.11, d=0.6\right]$, nor were they significant for tested items $\left[t_{(29)}=0.25, P=0.81, d=0.08\right.$; Fig. 2].

We next asked whether relative PM restudy benefits extended to the 24-h group. We found no benefits using same contrasts as above [restudy 24-h AM versus PM: $t_{(31)}=0.03, P=0.98, d=0.01$;

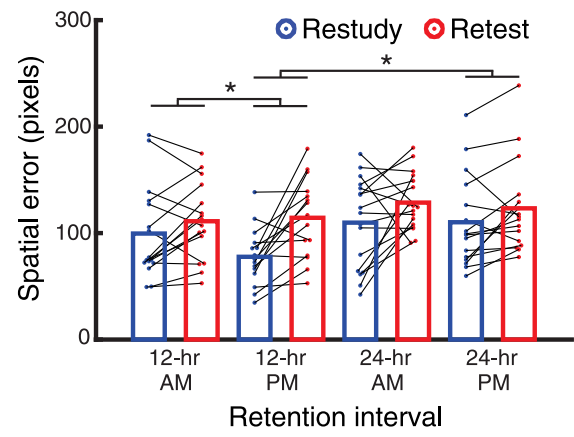

Figure 2. Comparisons between retention intervals with sleep versus wake on recall of restudied (blue) and retested information (red). Better recall corresponds to less spatial error as depicted on the $y$-axis. In the 12-h PM group, in which the retention interval included overnight sleep, memory was superior for restudied information compared to retested information. This restudy versus retest effect was reduced in the 12-h AM group. The effect was also reduced in the 24-h PM group, suggesting that additional wake impaired restudied more than retested information. Additionally, there were interactions between restudy and retest in the 12-h PM group versus the 12-h AM group and 24-h PM group (not indicated in figure; see text). All horizontal bars indicate significant contrasts at the $P<0.05$ level. 
retest 24-h AM versus PM: $t_{(31)}=0.43, P=0.67, d=0.15$; main effect of memory strategy: $F_{(1,31)}=7.14, P=0.01$; no main effect of time of encoding: $F_{(1,31)}=0.04, P=0.84$; interaction between restudy and retest 24 -h AM versus PM: $\left.F_{(1,31)}=0.23, P=0.64\right]$. This finding suggests the relative benefit sleep confers after learning for restudied items wanes after longer intervals, perhaps because the amount of intervening sleep did not differ between the 24-h AM and PM groups.

\section{Wake impaired memory for restudied relative to retested information}

With a 12-h delay that included sleep, restudied information had the advantage over retested information, but the 12-h groups alone cannot distinguish between whether (a) sleep aids restudied relative to retested information or (b) wake impairs restudied relative to retested information. If (a), we should see a restudy-retest difference between the 12-h AM and 24-h AM group, as the latter includes an extra interval of sleep. If (b), we should see a restudyretest difference between the 12-h PM and 24-h PM groups, as the latter includes an extra interval of wake. We first ran a two-way, retention interval (12-h versus $24-\mathrm{h}) \times$ memory strategy (S versus T) ANOVA within the PM encoding groups. Critically, we found a significant interaction $\left[F_{(1,29)}=4.5, P=0.043\right]$ (main effects: retention interval $\left[F_{(1,29)}=2.7, P=0.11\right]$; memory strategy: $\left[F_{(1,29)}=19.2, P<\right.$ 0.001]). A two-way, retention interval (12-h versus $24-\mathrm{h}) \times$ memory strategy (S versus $\mathrm{T}$ ) ANOVA within the AM encoding groups revealed no significant interaction $\left[F_{(1,31)}=0.34, P=0.56\right]$ (main effects: retention interval $\left[F_{(1,31)}=1.4, P=0.24\right]$; memory strategy: $\left.\left[F_{(1,31)}=6.1, P=0.02\right]\right)$. Results thus imply that wakeful interference specifically reverses the recall advantage found after one night of sleep for restudied relative to retested information. These results suggest restudied (versus retested) items benefit most from sleep (versus wake) in the 12-h group, but that this benefit disappears in the 24 -h group.

\section{Memory performance declined over time and depended on relearning strategy}

The restudy procedure was superior to retesting at 12- and 24-h intervals (Fig. 2). As this finding is atypical in the testing effect literature, it is important to verify whether a standard testing effect could be observed in our paradigm. By examining memory after $1 \mathrm{wk}$ as well as after $5 \mathrm{~min}$, we were able to more fully characterize the time course of forgetting.

For all groups together, we examined memory for locations as a function of learning strategy and retention interval. We submitted spatial memory to a mixed two-way, 2 (strategy: $S$ versus T) $\times 4$ (retention interval: 5-min, 12-, 24-h, or 1-wk) ANOVA (Fig. 3). The main effect of learning strategy indicated that restudied items were recalled better than retested items $\left[F_{(1,102)}=13.5, P<0.001\right]$. The main effect of retention interval indicated that memory faded over time $\left[F_{(3,100)}=90.2, P<0.001\right]$. Crucially, the interaction between learning strategy and retention interval was significant $\left[F_{(3,100)}=37.2, P<0.001\right]$. Follow-up $t$-tests revealed subjects remembered restudied items better than retested items after 5-min, 12-, and 24-h delays and retested items better than restudied items after 1 wk (Fig. 3). See Table 1 for full details on the comparisons between $S$ and $T$ groups. That is, a typical testing effect was observed at the longest delay.

\section{Discussion}

The results support previous conceptualizations of the testing effect and have novel implications for understanding memory processing both during waking and sleep. First, sleep after learning

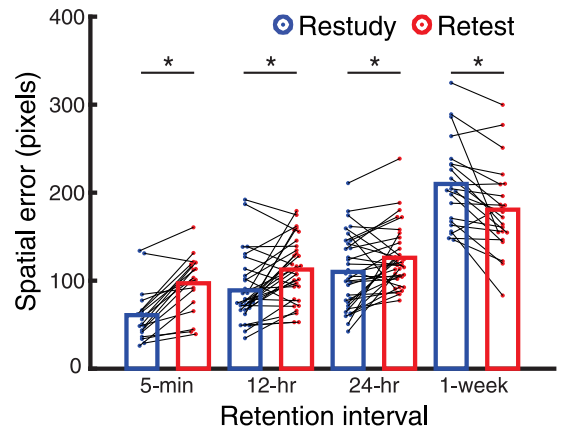

Figure 3. Restudied information (blue) faded more quickly than retested information (red). Initially, subjects recalled restudied better than retested information, but after $1 \mathrm{wk}$, those trends reverse. All horizontal bars indicate significant contrasts at the $P<0.05$ level. Note that this analysis collapses across AM and PM learning times to create overall 12- and 24-h groups. Across retention intervals there was a significant downward trend in memory and a significant interaction by learning strategy that are not depicted by interaction bars above (see text).

preferentially aids the recall of restudied versus retested information, compared to an equal amount of time without sleep. However, this effect wanes after $24 \mathrm{~h}$ when time asleep is approximately equalized between groups (one group with sleep soon after learning and the other much later). Control analyses verified that these effects could not be due to circadian differences in learning. Second, memory was better for restudying compared to retesting at retention intervals of $1 \mathrm{~d}$ or less $(5 \mathrm{~min}, 12 \mathrm{~h}$, or $24 \mathrm{~h}$ ) and for retesting compared to restudying at $1 \mathrm{wk}$.

\section{Sleep effects}

We found the advantage for restudied over retested information was greater in the PM than AM group. These results replicate the pattern shown with verbal memory by Bäuml et al. (2014) and extend this evidence to spatial memories. Over the second 12-h interval, we found a decrease in memory across the additional waking interval from the 12-h PM group to the 24-h PM group but not the 12-h AM to the 24-h AM group, suggesting the prolonged interference accruing during wake plays a stronger role in increasing the relative preservation of retest to restudy items than sleep does in decreasing it. Thus, the current findings support an alternative hypothesis offered by Bäuml et al. (2014) that wakeful interference differentially impairs restudied information.

It may seem surprising that sleep does not confer much benefit to retested items in the present study, as measuring memory change from before to after an interval containing wake or sleep is a standard way to assess the impact of sleep (Plihal and Born 1997, 1999; Payne et al. 2008). However, this relative nonbenefit for retested items is present in data from Bäuml et al. (2014) as well as two other studies investigating interactions between practiced and unpracticed memories and sleep (Racsmány, Conway et al. 2010; Abel and Bäuml 2013). In accord with these ideas, memory reactivation occurs less frequently for neuronal traces that have already undergone substantial stabilization during wake (van de Ven et al. 2016). Therefore, the impact of sleep wanes with more testing, such that sleep may preferentially benefit memories when they have not previously undergone extensive testing.

This interpretation plays into a proposal about retrieval and consolidation that diverges strongly from an account whereby retrieved information becomes "tagged" for additional processing during sleep (as in Redondo and Morris 2011). If retrieval preferentially tags memories for further processing, sleep should enhance the relative preservation of retrieved memories. The current results 
Table 1. Raw data and within-subject contrasts between restudy and retest from every condition

\begin{tabular}{|c|c|c|c|c|}
\hline & \multicolumn{4}{|c|}{ Spatial memory error } \\
\hline & $12 \mathrm{~h} \mathrm{AM}$ & 12 h PM & $24 \mathrm{~h} \mathrm{AM}$ & $24 \mathrm{~h} \mathrm{PM}$ \\
\hline Restudy & 99.56 & 77.72 & 109.81 & 110.19 \\
\hline SEM & 11.08 & 6.97 & 10.22 & 10.84 \\
\hline Retest & 111.13 & 114.37 & 128.63 & 123.26 \\
\hline SEM & 9.01 & 9.60 & 6.48 & 10.85 \\
\hline $\boldsymbol{t}$ & 1.63 & 3.89 & 1.87 & 2.09 \\
\hline$p$ & 0.12 & $<0.01$ & 0.08 & 0.05 \\
\hline$d_{z}$ & 0.41 & 1.01 & 0.45 & 0.52 \\
\hline \multirow[t]{2}{*}{$d f$} & 15 & 14 & 16 & 15 \\
\hline & $5 \mathrm{~min}$ & $12 \mathrm{~h}$ & $24 \mathrm{~h}$ & $1 \mathrm{wk}$ \\
\hline Restudy & 60.83 & 88.99 & 109.99 & 209.90 \\
\hline SEM & 7.19 & 6.83 & 7.32 & 10.46 \\
\hline Retest & 97.06 & 112.70 & 126.02 & 180.70 \\
\hline SEM & 7.76 & 6.47 & 6.15 & 10.81 \\
\hline$t$ & 6.16 & 3.83 & 2.70 & 4.00 \\
\hline $\boldsymbol{p}$ & $<0.01$ & $<0.01$ & 0.01 & $<0.01$ \\
\hline$d_{z}$ & 1.45 & 0.69 & 0.47 & 0.85 \\
\hline$d f$ & 17 & 30 & 32 & 21 \\
\hline
\end{tabular}

Spatial memory values are shown from 12-h and 24-h AM and PM groups (above) and for 5-min, 12-, 24-h, and 1-wk groups (below). Effect sizes for within-subject contrasts are reported as $d_{z}$.

and the results of Bäuml et al. (2014) directly contradict such an account. Instead, the results support a new proposal that retrieval rapidly consolidates information during retrieval itself, making it less, rather than more, dependent on subsequent offline processing (Antony et al. 2017).

This recent proposal and the current results accord well with the bifurcation model of retrieval (Halamish and Bjork 2011; Kornell et al. 2011). This model suggests restudying strengthens all memories to a modest degree, whereas retesting (without feedback) strengthens correctly remembered memories to a strong degree while not affecting incorrectly remembered memories, thus bifurcating memory strengths for retrieved items. The model posits that memory decay causes items to fall below a memory threshold over time, accounting for why restudy is often better than retesting without feedback at short delays, but retesting is better at long delays. Here, sleep could reduce the rate of decay relative to wake, causing relative benefits for restudied over retested items.

Some studies have reported benefits after a retention delay of $24 \mathrm{~h}$ for sleeping directly after learning compared to sleeping in the latter portion of the interval (Benson and Feinberg 1977; Gais et al. 2006; Talamini et al. 2008; Payne et al. 2012a,b). These studies support the idea that sleep plays an active, versus a passive, role in memory consolidation, as the memory trace can become stabilized across sleep to a greater extent if sleep occurs soon after learning. Studies manipulating various facets of sleep show there is considerable evidence for sleep playing an active role in declarative memory processing (Ellenbogen et al. 2006; Marshall et al. 2006; Rasch et al. 2007; Rudoy et al. 2009; Oudiette et al. 2013; Creery et al. 2014). However, we witnessed no advantage for immediate sleep after $24 \mathrm{~h}$ for the relative preservation of restudied information (contrasting 24-h AM versus 24-h PM). These results do not seriously conflict with the idea that sleep plays an active role in memory consolidation, because both wakeful interference and sleep reactivation likely contribute to sleep-related memory benefits. Waking interference may have taken precedent here.

\section{Long-term benefits of testing}

In accord with previous studies (Roediger and Karpicke 2006a; Kornell et al. 2011; Bai et al. 2015), subjects remembered restudied information better at short and retested information at long retention intervals. However, one interesting feature of the current study is that retested items were not better than restudied items after $12 \mathrm{~h}$ or even $24 \mathrm{~h}$ as we hypothesized. We suggest this pattern reflects strong initial memory strength after training. Pilot subjects had very poor memory when we initiated memory tests without feedback after encoding 60 objects. Therefore, in the design we selected for the current experiment we asked subjects to successfully retrieve all objects twice with feedback before three additional restudy or retest-without-feedback events. This procedural feature likely caused a slower rate of forgetting than in other studies of the testing effect, thus prolonging the amount of time restudied information remained more recallable than retested information. Importantly, results from the 1-wk group substantiated the relative superiority of repeated testing in the current paradigm.

\section{Conclusion}

This study contributes to the literature in two major ways. First, results replicated findings that restudy improves memory in the short term and retesting improves memory in the long term, broadening the range of memory types by using a spatial task with object-location associations (Roediger and Karpicke 2006a; Kornell et al. 2011; Bai et al. 2015). Second, we built on the results of Bäuml et al. (2014) showing that sleep produces larger relative benefits for restudied than retested information. Our findings clarified that wake increases rather than sleep reduces the relative benefit of testing. We interpret these results to imply that the mechanism underlying long-term benefits of testing differs markedly from the mechanism proposed for important memories under the synaptic-tag-and-capture model (Redondo and Morris 2011). Though retrieval likely differs from sleep reactivation in important ways that remain to be discovered, the present results lend credence to the idea that retrieval acts as a consolidation event that solidifies information at the time of retrieval itself. Offline processing during sleep is akin to retrieval, and when memories are solidified during the day, they correspondingly benefit less from further offline processing.

\section{Materials and Methods}

\section{Subjects}

Individuals from an introductory psychology course participated $(N=104$, mean age $=19.0 \mathrm{yr}, 62$ female). Informed consent was obtained in advance and course credit was provided after completion. Data from three subjects were excluded for not returning for the test session. We included the following conditions: 12-h AM ( $n=$ 16); 12-h PM $(n=15) ; 24$-h AM $(n=17) ; 24$-h PM $(n=16) ; 5$-min $(n=18)$; and 1-wk: $(n=22)$.

\section{Stimuli}

A set of 60 color pictures of nameable objects (e.g., accordion, apple, giraffe) of various categories was used (Rossion and Pourtois 2004). Objects were presented against a background three-color grid $(600 \times 600$ pixels, or $21.4 \times 21.4 \mathrm{~cm}$, with each grid box 100 pixels in height; Fig. 1A). Each picture had a width of 150 pixels, a height of between 100 and 150 pixels, and a central red dot to indicate its precise location on the grid. This was done so as to not distort natural images by stretching them into square sizes.

\section{Design}

Subjects were assigned to learn at one of two initial learning times (9 AM or $9 \mathrm{PM}$ ). After initial learning (see below), each subject repeatedly studied or repeatedly tested on 30 items each (Fig. 1A) and returned to the laboratory after 12 or $24 \mathrm{~h}$ (Fig. 1B). In the additional groups, subjects learned and were tested after either $5 \mathrm{~min}$ or $1 \mathrm{wk}$. Learning and testing in the additional groups occurred at 
the same time of day (either AM or PM) to obtain circadian consistency with the previous groups (5-min: 10 of 18 in the AM; 1-wk: 11 of 22 in $\mathrm{AM}$ ).

\section{Procedure}

In the first part of the training session, subjects learned 60 objectlocation associations (Fig. 1A) in three blocks of 20 . They first viewed each object for 4 sec at a unique, randomly assigned location on the grid. After viewing all 20 locations, they tested on each object's location with feedback until they could place it within 150 pixels of its correct location twice in a row. After they successfully recalled the locations of all 20 objects within a block, they proceeded to the next block until all objects were learned. We settled on this procedure, wherein all items were tested before being either subsequently restudied or retested, after pilot testing showed subjects had very poor memory in the absence of this extensive training.

In the second part of the training session, subjects repeatedly studied or tested on each of the objects from the first part in a randomly intermixed fashion. Thirty objects from the first part of the training session were each pseudorandomly assigned to the restudy and retest conditions to match error between conditions. The pseudorandomization algorithm sorted the error of all objects from the first part of the experiment and randomly separated objects into restudy and retested conditions. For restudy, subjects viewed each object in its original location three times for 4 sec each in a random order. For retest, subjects practiced retrieving each object by dragging it from the center to their remembered location three times. These tests had no time limit and no feedback. Restudy and retest trials were intermixed in a different random order for each repetition.

Following the training session, subjects returned after one of four intervals for a final test. In this session, they recalled the location of each object once.

\section{Statistics}

Our primary measure involved calculating the Pythagorean distance in pixels between the original and guessed locations. Many contrasts used paired and unpaired $t$-tests between spatial memory error of restudied or retested information. To test interactions between learning time, retention interval, and memory strategy, we calculated ANOVAs using mean spatial error as the dependent variable with learning time (AM versus $\mathrm{PM}$ ) and retention interval (12-h versus $24-\mathrm{h}$ ) as between-subject contrasts and memory strategy ( $\mathrm{S}$ versus $\mathrm{T}$ ) as the within-subject contrast.

Analyses investigating how retention interval interacted with learning strategy used spatial memory error as the dependent variable in mixed, two-way ANOVAs, with learning strategy (restudy versus retest) as a within-subjects factor and retention interval (5-min, 12-, 24-h, versus 1-wk) as a between-subjects factor. We did not directly contrast the 5-min or 1-wk AM versus PM effects due to lack of statistical power.

For between-subject comparisons, Cohen's $d$ values were calculated by dividing the difference in group means by the pooled standard deviation. For within-subject comparisons, Cohen's $d_{z}$ values were calculated by subtracting group means, calculating the standard deviation of the subtracted mean, and dividing the subtracted mean by the standard deviation of the subtracted mean.

\section{Acknowledgments}

We are grateful for support from NIH grant T32-AG020418 and F31-MH100958 (J.W.A.), NSF grant BCS-1461088 (K.A.P.), and a Faculty Research Grant from the University Research Grants Committee at Northwestern University (K.A.P.). The authors thank Kristine Kohlhepp and Tom White for help with data collection.

Author contributions: J.W.A. and K.A.P. designed the research, J.W.A. performed the research and analyzed the data, J.W.A. and K.A.P. wrote the paper.

\section{References}

Abbott EE. 1909. On the analysis of the factors of recall in the learning process. Psychol Monogr 11: 159-177.

Abel M, Bäuml KHT. 2013. Sleep can eliminate list-method directed forgetting. J Exp Psychol Learn Mem Cogn 39: 946-952.

Antony JW, Ferreira CS, Norman KA, Wimber M. 2017. Retrieval as a fast route to memory consolidation. Trends in Cogn Sci 21: 573-576.

Bai C-H, Bridger EK, Zimmer HD, Mecklinger A. 2015. The beneficial effect of testing: an event-related potential study. Front Behav Neurosci 9: 248.

Bäuml KHT, Holterman C, Abel M. 2014. Sleep can reduce the testing effect: it enhances recall of restudied items but can leave recall of retrieved items unaffected. J Exp Psychol Learn Mem Cogn 40: 1568-1581.

Benson K, Feinberg I. 1977. The beneficial effect of sleep in an extended Jenkins and Dallenbach paradigm. Psychophysiology 14: 375-384.

Carpenter SK, Kelly JW. 2012. Tests enhance retention and transfer of spatial learning. Psychon Bull Rev 19: 443-448.

Carpenter SK, Pashler H, Wixted JT, Vul E. 2008. The effects of tests on learning and forgetting. Mem Cognit 36: 438-448.

Carrier M, Pashler H. 1992. The influence of retrieval on retention. Mem Cognit 20: 633-642.

Creery JD, Oudiette D, Antony JW, Paller KA. 2014. Targeted memory reactivation during sleep depends on prior learning. Sleep 38: 755-763.

Diekelmann S, Born J. 2010. The memory function of sleep. Nat Rev Neurosci 11: $114-126$.

Ellenbogen JM, Hulbert JC, Stickgold R, Dinges DF, Thompson-Schill SL. 2006. Interfering with theories of sleep and memory: sleep, declarative memory, and associative interference. Curr Biol 16: 1290-1294.

Gais S, Lucas B, Born J. 2006. Sleep after learning aids memory recall. Learn Mem 13: 259-262.

Gates AI. 1917. Recitation as a factor in memorizing. Arch Psychol 6: 1-104.

Halamish V, Bjork RA. 2011. When does testing enhance retention? A distribution-based interpretation of retrieval as a memory modifier. J Exp Psychol Learn Mem Cogn 37: 801-812.

Jenkins J, Dallenbach K. 1924. Obliviscence during sleep and waking. Am J Psychol 35: 605-612.

Karpicke JD, Roediger HL. 2008. The critical importance of retrieval for learning. Science 319: 966-968.

Kornell N, Bjork RA, Garcia MA. 2011. Why tests appear to prevent forgetting: a distribution-based bifurcation model. J Mem Lang 65 : 85-97.

Marshall L, Helgadóttir H, Mölle M, Born J. 2006. Boosting slow oscillations during sleep potentiates memory. Nature 444: 610-613.

Norman KA, Newman EL, Perotte AJ. 2005. Methods for reducing interference in the Complementary Learning Systems model: oscillating inhibition and autonomous memory rehearsal. Neural Netw 18: 1212-1228.

Oudiette D, Paller KA. 2013. Upgrading the sleeping brain with targeted memory reactivation. Trends Cogn Sci 17: 142-149.

Oudiette D, Antony JW, Creery JD, Paller KA. 2013. The role of memory reactivation during wakefulness and sleep in determining which memories endure. J Neurosci 33: 6672-6678.

Payne JD, Stickgold R, Swanberg K, Kensinger EA. 2008. Sleep preferentially enhances memory for emotional components of scenes. Psychol Sci 19: 781-788.

Payne JD, Chambers AM, Kensinger EA. 2012a. Sleep promotes lasting changes in selective memory for emotional scenes. Front Integr Neurosci 6: $1-11$.

Payne JD, Tucker MA, Ellenbogen JM, Wamsley EJ, Walker MP, Schacter DL, Stickgold R. 2012b. Memory for semantically related and unrelated declarative information: the benefit of sleep, the cost of wake. PLoS One 7: e33079.

Plihal W, Born J. 1997. Effects of early and late nocturnal sleep on declarative and procedural memory. J Cogn Neurosci 9: 534-547.

Plihal W, Born J. 1999. Effects of early and late nocturnal sleep on priming and spatial memory. Psychophysiology 36: 571-582.

Potts R, Shanks DR. 2012. Can testing immunize memories against interference? J Exp Psychol Learn Mem Cogn 38: 1780-1785.

Racsmány M, Conway MA, Demeter G. 2010. Consolidation of episodic memories during sleep: long-term effects of retrieval practice. Psychol Sci 21: 80-85.

Rasch B, Büchel C, Gais S, Born J. 2007. Odor cues during slow-wave sleep prompt declarative memory consolidation. Science 315: 1426-1429.

Redondo RL, Morris RGM. 2011. Making memories last: the synaptic tagging and capture hypothesis. Nat Rev Neurosci 12: 17-30.

Roediger HL, Karpicke JD. 2006a. Test-enhanced learning: taking memory tests improves long-term retention. Psychol Sci 17: 249-255.

Roediger HL, Karpicke JD. 2006b. The power of testing memory: basic research and implications for educational practice. Perspect Psychol Sci 1: 181-210. 
Rossion B, Pourtois G. 2004. Revisiting Snodgrass and Vanderwart's object pictorial set: the role of surface detail in basic-level object recognition. Perception 33: 217-236.

Rudoy J, Voss J, Westerberg C, Paller K. 2009. Strengthening individual memories by reactivating them during sleep. Science 326: 1079.

Schmidt C, Peigneux P, Muto V, Schenkel M, Knoblauch V, Münch M, de Quervain DJ, Wirz-Justice A, Cajochen C. 2006. Encoding difficulty promotes postlearning changes in sleep spindle activity during napping. J Neurosci 26: 8976-8982.

Spitzer HF. 1939. Studies in retention. Educ Psychol 30: 641-656.

Talamini LM, Nieuwenhuis IL, Takashima A, Jensen O. 2008. Sleep directly following learning benefits consolidation of spatial associative memory. Learn Mem 15: 233-237. van de Ven GM, Trouche S, McNamara CG, Allen K, Dupret D. 2016. Hippocampal offline reactivation consolidates recently formed cell assembly patterns during sharp wave-ripples. Neuron 92: 968-974.

Wheeler MA, Ewers M, Buonanno JF. 2003. Different rates of forgetting following study versus test trials. Memory 11: $571-580$.

Yaroush R, Sullivan MJ, Ekstrand BR. 1971. Effect of sleep on memory: II. Differential effect of the first and second half of the night. J Exp Psychol 88: $361-366$.

Received July 1, 2017; accepted in revised form February 5, 2018. 


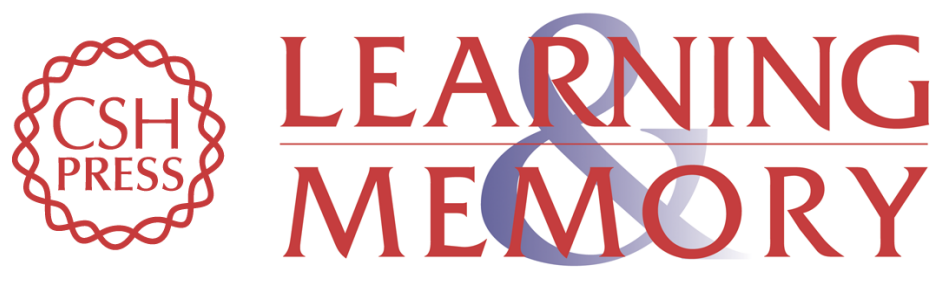

\section{Retrieval and sleep both counteract the forgetting of spatial information}

James W. Antony and Ken A. Paller

Learn. Mem. 2018, 25:

Access the most recent version at doi:10.1101/lm.046268.117

References This article cites 41 articles, 7 of which can be accessed free at:

http://learnmem.cshlp.org/content/25/6/258.full.html\#ref-list-1

Creative This article is distributed exclusively by Cold Spring Harbor Laboratory Press for the

Commons first 12 months after the full-issue publication date (see

License

http://learnmem.cshlp.org/site/misc/terms.xhtml). After 12 months, it is available under a Creative Commons License (Attribution-NonCommercial 4.0 International), as described at http://creativecommons.org/licenses/by-nc/4.0/.

Email Alerting Receive free email alerts when new articles cite this article - sign up in the box at the Service top right corner of the article or click here. 